\title{
Integrated electrochemical-biological process as an alternative mean for ammonia monitoring during anaerobic digestion of organic wastes
}

\author{
Zhao, Nannan; Li, Xiaohu; Jin, Xiangdan; Angelidaki, Irini; Zhang, Yifeng
}

Published in:

Chemosphere

Link to article, DOI:

10.1016/j.chemosphere.2017.12.139

Publication date:

2017

Document Version

Peer reviewed version

Link back to DTU Orbit

Citation (APA):

Zhao, N., Li, X., Jin, X., Angelidaki, I., \& Zhang, Y. (2017). Integrated electrochemical-biological process as an alternative mean for ammonia monitoring during anaerobic digestion of organic wastes. Chemosphere, 195, 735-741. https://doi.org/10.1016/j.chemosphere.2017.12.139

\section{General rights}

Copyright and moral rights for the publications made accessible in the public portal are retained by the authors and/or other copyright owners and it is a condition of accessing publications that users recognise and abide by the legal requirements associated with these rights.

- Users may download and print one copy of any publication from the public portal for the purpose of private study or research.

- You may not further distribute the material or use it for any profit-making activity or commercial gain

- You may freely distribute the URL identifying the publication in the public portal 


\title{
Integrated electrochemical-biological process as an alternative mean for ammonia monitoring during anaerobic digestion of organic wastes
}

\author{
Nannan Zhao, Xiaohu Li, Xiangdan Jin, Irini Angelidaki, Yifeng Zhang* \\ Department of Environmental Engineering, Technical University of Denmark, DK-2800 Lyngby, Denmark
}

${ }^{*}$ Corresponding author, Tel.: +45 45251410; fax: +4545932850.

E-mail address: yifz@env.dtu.dk; yifzmfc@gmail.com (Yifeng Zhang) 


\begin{abstract}
Ammonia monitoring is important to control anaerobic digestion (AD) process due to inhibition effect. Here, an electrolysis cell (EC) was integrated with a complete nitrification reactor as an alternative approach for online monitoring of ammonia during $\mathrm{AD}$ processes. The $\mathrm{AD}$ effluent was pumped into nitrification reactor to convert ammonia to nitrate, followed by the introduction of nitrate-rich effluent to EC cathode. It was first evaluated with synthetic ammonia-rich digesters and was observed that the current at 5 min were linearly corresponding to the ammonia levels (from 0 to $7.5 \mathrm{mM} \mathrm{NH}_{4}{ }^{+}-\mathrm{N}, \mathrm{R}^{2}=0.9673$ ). The linear relationship was always observed regardless of different wastewater $\mathrm{pH}$ and external voltage. Pre-removal of other electron acceptors from digestate at cathode could eliminate their disturbances to sensor performance. Finally, the accuracy of biosensor was verified with real digestate test. The simple and reliable biosensor showed great promising for online ammonia monitoring of $\mathrm{AD}$ processes.
\end{abstract}

\title{
Keywords
}

Biomonitoring; Ammonia; Electrolysis cell; Nitrification; Anaerobic digestion; Digestate 


\section{Introduction}

Anaerobic digestion (AD), as a sustainable technology to produce biogas from various wastes such as manure, solid waste and sludge, is becoming more and more attractive across the world (Chatterjee and Mazumder, 2016; Choong et al., 2016; Rayner et al., 2017; Senghor et al., 2017). However, ammonia coming from degradation of protein in $\mathrm{AD}$ substrate could be an inhibitor for $\mathrm{AD}$ process (Angelidaki and Ahring, 1994; Hansen et al., 1998; Rajagopal et al., 2013). As reported before, low free ammonia concentrations (e.g. $100 \mathrm{mg}-\mathrm{N} / \mathrm{L}$ ) could inhibit an unadapted AD process (Hansen et al., 1998). Therefore, ammonia monitoring is significantly important to maintain stability of AD. Currently, the common methods to test the ammonia in aquaculture include colorimeter procedure (Nessler, phenate, and salicylate methods), ion-selective electrode for $\mathrm{NH}_{4}{ }^{+}$, and test kits relying on the Nessler or salicylate methods (Krug et al., 1979; Le and Boyd, 2012; Zhou and Boyd, 2016). However, there are still some drawbacks among these methods. Firstly, the accuracy of colorimeter methods is easily disturbed by the sample color or turbidity. Secondly, the issue of disposal of hazardous waste, which increases the complexity and operation cost, becomes a sever concern in Nessler method. Thirdly, most of the colorimeter methods need extra sample preparations (e.g., membrane filtration) which are time-consuming and costly. Lastly, the ion-selective electrode is strongly affected by the sodium and potassium although with high precision and wide detection range. New conductive materials have also been developed to monitor dissolved ammonia in water, but the synthesis of materials and sensor fabrication are still complicated and the costs are relatively high (Tao et al., 2006; Huang et al., 2016). Thus, development of an alternative environmental-friendly, simple, rapid, online and reliable ammonia sensor is in urgent need for environmental monitoring and water quality control.

On the other hand, electrochemical system has been widely applied into ammonia sensor field because of their high selectivity and sensitivity (Ribeiro et al., 2012; Herzog, 2015; Zhybak et al., 2016; Ning et al., 2017). The electrochemical ammonia sensors, which are based on the ammonia ion transfer reactions across different electrolyte interfaces, mainly include potentiometric and amperometric methods (Bertocchi et al., 1996; Abass et al., 1998; Zolotov et al., 2014; Herzog, 2015). In Luo's research (Luo and Do, 2006), two kinds of polyaniline-poly composite films were prepared and they exhibited a high sensitivity of $\mathrm{NH}_{4}{ }^{+}-\mathrm{N}$ up 
to $100 \mathrm{mM}$. Riberiro (Ribeiro et al., 2012) also developed an amperometric sensor to detect ammonia concentrations in the range from 4.2 to $66 \mathrm{uM}$. Most of the electrochemical ammonias sensors were focused on the development of new nanomaterials or fabricating electrodes. Although with high sensitivity and selectivity, these electrochemical sensors still require tedious and complex fabrication process and high consumption of nanomaterials.

Recently, nitrate as an alternative electron acceptor was removed at cathode of an EC reactor, which demonstrated the cathodic nitrate reduction in EC (Abdallah et al., 2014; Radjenovic and Sedlak, 2015; Rajmohan et al., 2016). In biological pathway, ammonia could be aerobically oxidized to nitrate through nitrification process (Zhang et al., 2009; Samarasinghe et al., 2016; Wang et al., 2016). Therefore, coupling nitrification stage with electrochemical nitrate reduction could be a possible way to monitor ammonium during biogas production. Compared to the conventional methods and current electrochemical ammonia sensors, it may offer a fast, environmentally friendly and simple potential approach for monitoring ammonia during $\mathrm{AD}$. To the best of our knowledge, such integrated system has never been explored before.

The aim of present study is to develop an alternative and potentially sustainable approach for ammonia monitoring during AD process. To achieve this goal, an integrated EC-nitrification system was constructed. In this sensor, ammonia in the AD digester was firstly oxidized to nitrate in nitrification reactor. The effluent enriched with nitrate was introduced into cathode of EC reactor for further reduction. Firstly, the sensor performance was explored with synthetic wastewater, in terms of nitrification efficiency, ammonia detection range, response time and operational stability. The effects of external power supply and $\mathrm{pH}$ on sensor performance were also investigated. Besides, considering other possible electron acceptors in AD digester, the digester was pumped into cathode of EC first to eliminate effects. Finally, the new sensor was tested with real $\mathrm{AD}$ digesters to verify its reliability. The application of this new sensor may have the potential to provide an online and reliable approach to monitor ammonia, which could be helpful to maintain AD stability. 


\section{Material and methods}

\subsection{Reactor configuration and operation}

An EC reactor, made of nonconductive polycarbonate plates, was a rectangular reactor composed of anode chamber $(50 \mathrm{ml})$ and cathode chamber $(100 \mathrm{ml})$ (Fig.1). The electrode materials were a titanium woven wire mesh ( $4 \times 5 \mathrm{~cm}, 0.15 \mathrm{~mm}$ aperture, William Gregor Limited, London) coated with $0.5 \mathrm{mg} / \mathrm{cm}^{2} \mathrm{Pt}$ for cathode, and a Titanium mesh electrode coated with Ir MMO (dimensions: $4 \times 5 \mathrm{~cm} ; 1 \mathrm{~mm}$ thickness; specific surface area $1.0 \mathrm{~m}^{2} / \mathrm{m}^{2}$, Magneto Special Anodes, The Netherlands) for anode. The anode chamber was filled with 50mM PBS (pH-7) and cathode chamber was filled with synthetic wastewater. The synthetic wastewater was prepared with ammonia chloride being dissolved into tap water at different ammonia levels. Two chambers were separated by a cation exchange membrane (CEM, CMI 7000, Membrane international, NJ). The rubber gaskets and screws were used to avoid leakage during the assembling. The membrane was put in $50 \mathrm{M} \mathrm{NaCl}$ solution for 24 hours, and then soaked in distilled water until use. A power supply (NEWARE Battery testing system 7.5.X, China) was used to provide the external voltage to the reactor. During the study of influence of other electron acceptors on sensor performance, an anion membrane (AEM) was used to avoid $\mathrm{NH}_{4}{ }^{+}$ migration.

A lab-scale nitrification reactor was set up to complete the oxidation from ammonia to nitrate. A glass bottle $(500 \mathrm{ml})$ was used for the reactor, and the effluent of a membrane bio-reactor (MBR) was used as the inoculum to set up this nitrification stage. The characteristics of inoculum were $2.5 \mathrm{~g} / \mathrm{L}$ (total solid content) and $\mathrm{pH}$ 7.04. During the enrichment of nitrification bacteria, the medium, which contained $2.45 \mathrm{~g} / \mathrm{L}$ $\mathrm{NaH}_{2} \mathrm{PO}_{4}, 4.58 \mathrm{~g} / \mathrm{L} \mathrm{Na}_{2} \mathrm{HPO}_{4}, 0.1 \mathrm{~g} / \mathrm{L} \mathrm{KCl}, 0.1 \mathrm{~g} / \mathrm{L} \mathrm{MgCl} \cdot 6 \mathrm{H}_{2} \mathrm{O}, 0.1 \mathrm{~g} / \mathrm{L} \mathrm{CaCl}{ }_{2} \cdot 2 \mathrm{H}_{2} \mathrm{O}, 12.5 \mathrm{ml} / \mathrm{L}$ mineral solution and vitamin solution as describe before, was used. $\mathrm{NaHCO}_{3}(2 \mathrm{~g} / \mathrm{L})$ was used as the carbon source and electron donor. The aeration was obtained directly from the air as it was open to air and the solution was fully mixed by magnetic stirrer.

In the investigation of linear relationship between current and ammonia concentration, the synthetic wastewater with different ammonia levels $\left(0-7.5 \mathrm{mM} \mathrm{NH}_{4}{ }^{+}-\mathrm{N}\right)$ was pumped into nitrification reactor first and then the effluent was purged with nitrogen and introduced into cathode chamber of EC. The current in circuit 
was recorded by NEWARE Battery testing system 7.5.X. In one set of tests, the external voltage was set at $1.5 \mathrm{~V}, 1.8 \mathrm{~V}, 2 \mathrm{~V}$ and $2.3 \mathrm{~V}$ to elucidate the effect of external power on sensor performance. Then the effect

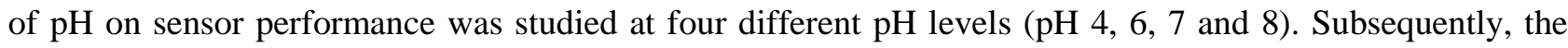
pretreatment of sensor was evaluated by adding $\mathrm{Fe}^{3+}$ and $\mathrm{NO}_{3}{ }^{-}$to the synthetic wastewater. To verify the accuracy of sensor, it was tested with two real AD effluents. One was collected from a lab-scale AD reactor for biogas upgrading which was operated at $37^{\circ} \mathrm{C}$ (noted as $\mathrm{AD}$ effluent 1 ). The other one was taken from a thermophilic lab-scale $\mathrm{AD}$ reactor fed with manure $\left(55^{\circ} \mathrm{C}\right)$ (noted as $\mathrm{AD}$ effluent 2). All experiments were carried out in duplicate at room temperature.

In the statistical analysis, the student's t-test was applied and P-values $<0.05$ were considered to have significance effect on the response, while values $>0.1$ indicate the variables are not significant.

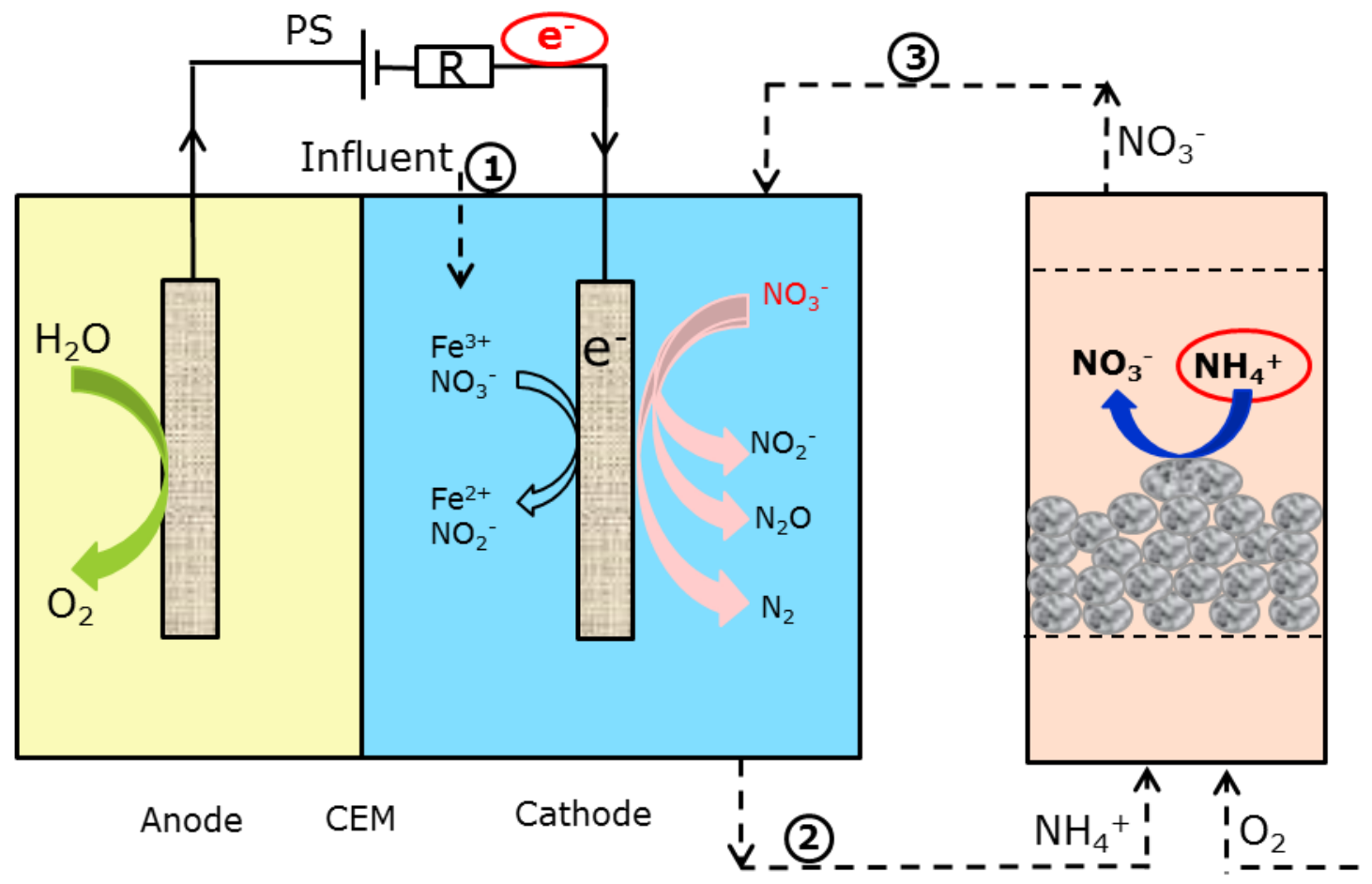

\section{Electrochemical system Nitrification Reactor}

Figure. 1 Schematic diagram of the integrated EC-nitrification system. CEM: the cation exchange membrane. 


\subsection{Electrochemical analysis and calculations}

The $\mathrm{pH}$ and conductivity of tested solution were measured by a PHM $210 \mathrm{pH}$ meter (Radiometer) and a CDM 83 conductivity meter (Radiometer), respectively. The concentrations of ammonia, nitrate and $\mathrm{Fe}^{3+}$ were determined by colorimetric test kits (Spectroquant 00683, 09713, Merck, Germany). The current in EC circuit was recorded by NEWARE Battery testing system 7.5.X every $1 \mathrm{~min}$.

\section{Results and discussion}

\subsection{Nitrification stage}

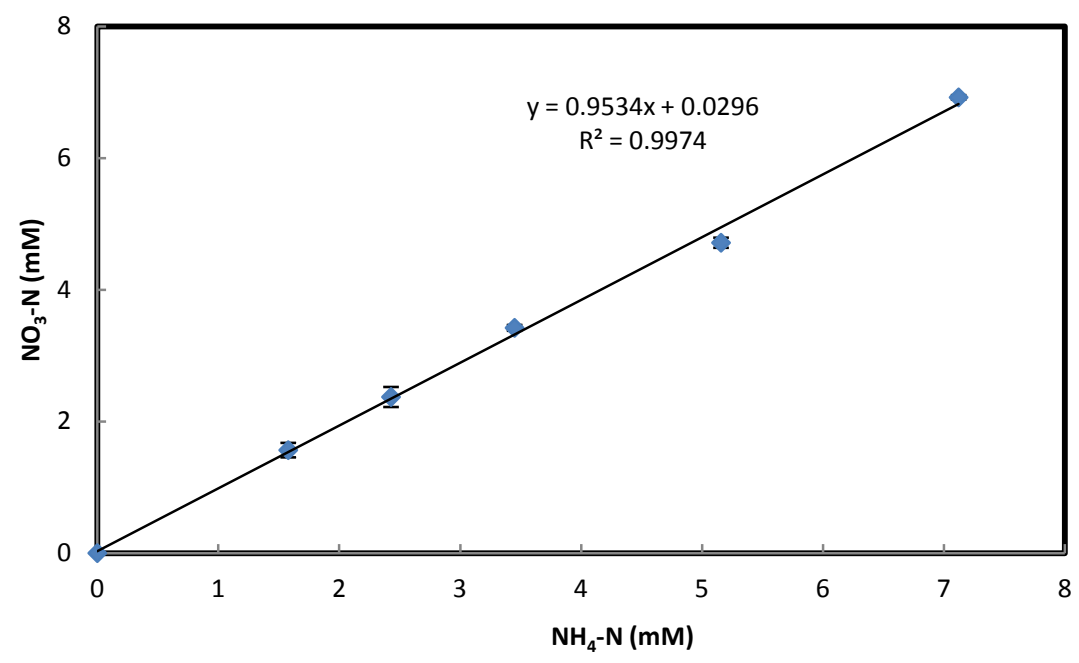

Figure. 2 The correlation between initial ammonia level and accumulated nitrate concentration in nitrification reactor.

Fig.2 depicts the performance of lab-scale nitrification reactor. All the nitrifying process was completed within four hours. As shown, when ammonia level changed from 0 to $7.1 \mathrm{mM} \mathrm{NH}_{4}{ }^{+}-\mathrm{N}$, the corresponding nitrate concentrations varied from 0 to $6.9 \mathrm{mM} \mathrm{NO}_{3}{ }^{-} \mathrm{N}$, with a stable conversion rate. The line slope is 0.9534, illustrating almost the same amount of ammonia to nitrate numerically. The high conversion efficiency (over 90\%) was in agreement with literature (Tarre and Green, 2004). However, compared to other study (Zhang et al., 2009), the nitrification rate obtained here was a little lower $\left(581.4 \mathrm{~g} / \mathrm{m}^{3} \cdot \mathrm{d}\right)$ because of the possible different operational parameters such as the different attachment forms of nitrifying bacteria, 
$\mathrm{pH}$ and dissolve oxygen concentrations. As demonstrated before, influent $\mathrm{pH}$ has a significant impact on the performance of a membrane-aerated bioreactor with respect to nitrification rate (Shanahan and Semmens, 2015). Also, biofilm performs better than suspended-biomass in terms of nitrification rate (Tarre and Green, 2004). Nevertheless, the results above had already offered enough proof for the sensor concept. Considering aerated nitrification process has already been developed commercially with a high rate, it could be replaced with a commercialized nitrification reactor in the future industrial application. In a short conclusion, the high and stable nitrification efficiency provided the insurance of the following investigation of relationship between current and ammonia concentration.

\subsection{The performance of EC: correlation between ammonia level and current}
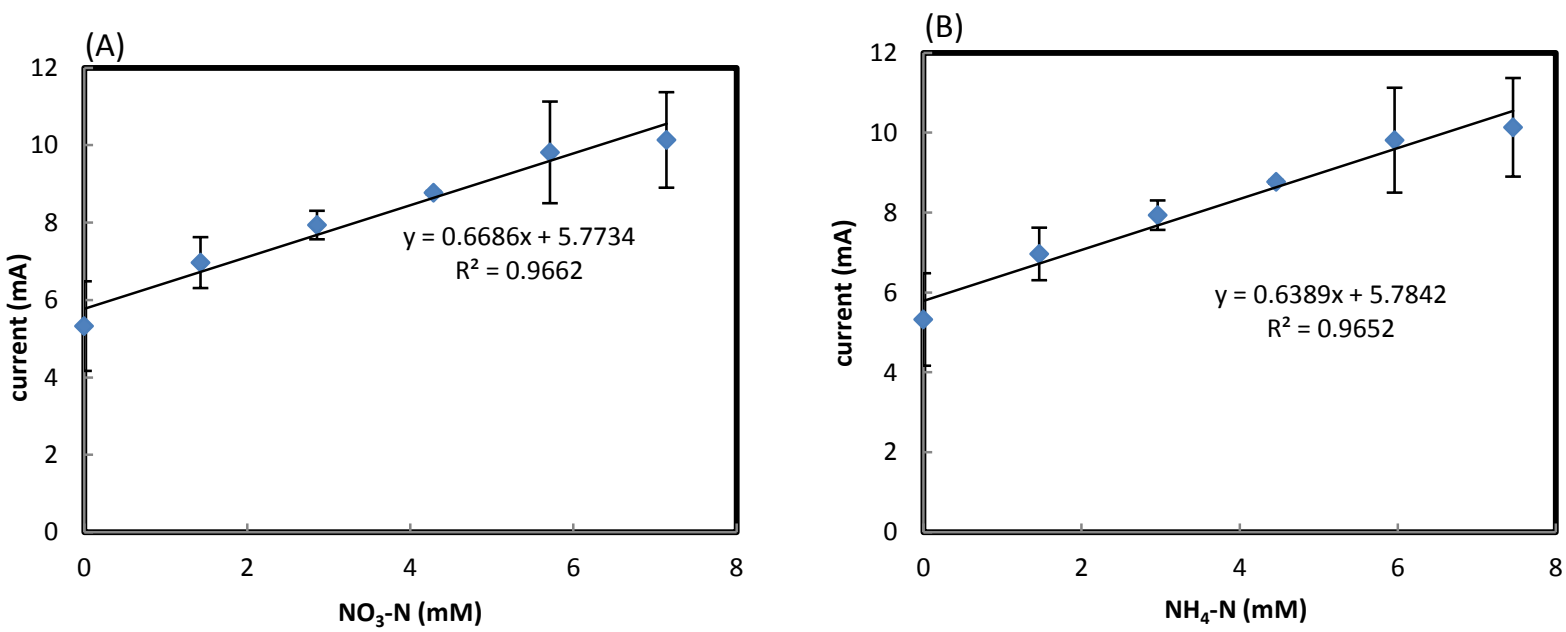

Figure. 3 The linear relationship between current and nitrate levels (A) and ammonia levels (B) at external power supply of $1.8 \mathrm{~V}$ and $\mathrm{pH}$ 6. (1.4 to $\left.7 \mathrm{mM} \mathrm{NH}_{4}{ }^{+}-\mathrm{N}\right)$

The effluent containing nitrate from nitrification process was firstly flushed with nitrogen and then introduced into cathode chamber of EC. A fast response of current of EC to a stepwise increase from 0 to 7.1 $\mathrm{mM} \mathrm{NO}_{3}{ }^{-} \mathrm{N}$ was observed within 5 minutes. Fig.3 (A) and (B) illustrate the current variation of EC versus nitrate and ammonia concentration, respectively. It is clear from Fig.3 (A) and (B) that the current showed positive slopes with nitrate and ammonia level increasing. The current linearly increased $(5.329 \pm 1.157$ to $10.139 \pm 1.233 \mathrm{~mA}, \mathrm{R}^{2}=0.9673$ ) when ammonia levels ranged from 0 to $7.5 \mathrm{mM} \mathrm{NH}_{4}{ }^{+} \mathrm{N}$. The slopes for 
current and nitrate, ammonia levels were 0.6686 and 0.6389 , respectively. The positive slopes meant with ammonia or nitrate concentrations increasing, the corresponding currents showed a gradual linear increase as well. The current, as a representative of the numbers of electron per second in the circuit, was closely connected with external voltage and amount of electron acceptors in cathode. Considering the stable external power of $1.8 \mathrm{~V}$ in this case, the different current response was mainly contributed by the different electron acceptor (i.e., nitrate) in cathode. In addition, the range of detection could reach up to $7.5 \mathrm{mM} \mathrm{NH}_{4}{ }^{+}-\mathrm{N}$, which was much higher compared to other electrochemical ammonia sensor (0.3 mM) (Ribeiro et al., 2012). The above results demonstrated a good linear relationship between current generation and initial ammonia concentrations ranging from 0 to $7.5 \mathrm{mM}$. Contrast to the conventional testing approaches (e.g. testing kits and titration), the new biosensor developed here exhibited merits of rapid and real time monitoring properties. Compared to other fast electrochemical ammonia sensor, this new sensor also shows great advantages of relatively low cost and high sensitivity. Overall, it has been demonstrated that the new developed sensor has a good performance in monitoring ammonia and especially is most suitable for high ammonia concentration detection.

\subsection{Monitoring performance under different operational conditions}

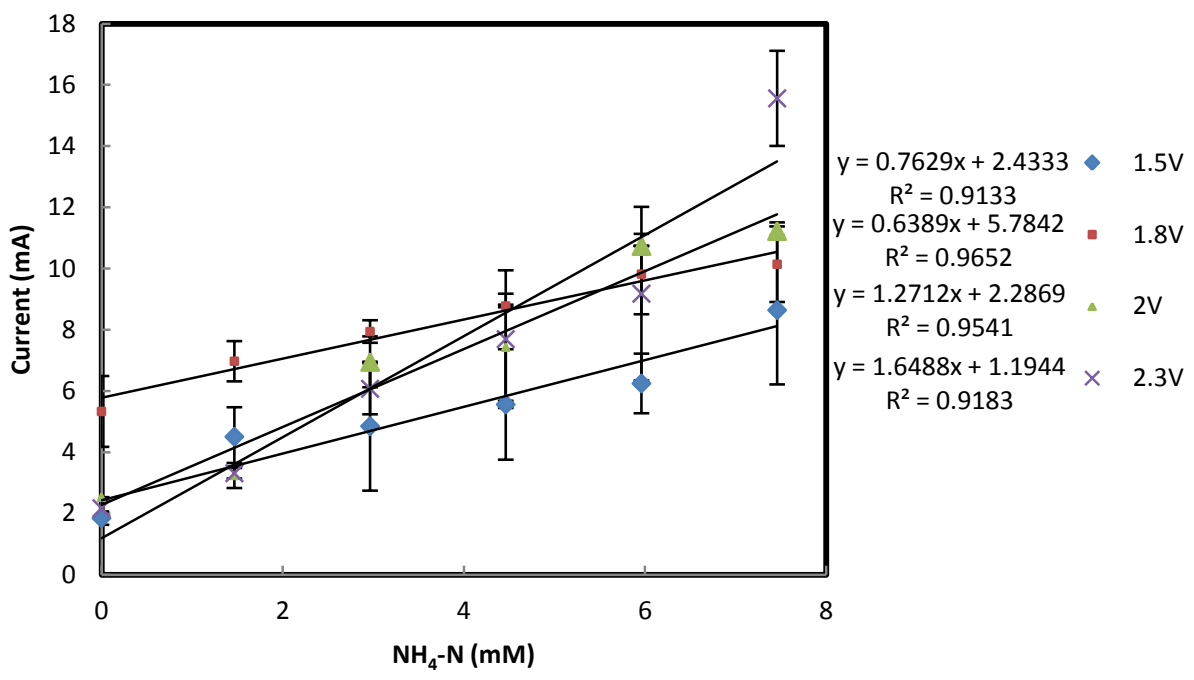


Figure. 4 Effect of external applied voltage on the performance of ammonia sensor. The initial $\mathrm{pH}$ of the nitrification effluent is 6 in the cathode.

Since the current in circuit is highly related to external voltage, a series of tests were conducted at varied external applied voltages ( $1.5 \mathrm{~V}$ to $2.3 \mathrm{~V})$. As shown in Fig.4, the currents always showed positive slopes with respect to ammonia levels regardless of the applied voltages. The slopes at $1.5,1.8,2$ and $2.3 \mathrm{~V}$ were $0.7629,0.6389,1.2712$ and 1.6488 , respectively. The highest slope appeared at the external voltage of $2.3 \mathrm{~V}$, while the slopes for $1.5 \mathrm{~V}$ and $1.8 \mathrm{~V}$ were relatively lower. The higher slope usually meant a higher current generation. For example, at $7.5 \mathrm{mM} \mathrm{NH}_{4}{ }^{+}-\mathrm{N}$, the currents at 1.5, 1.8, 2 and $2.3 \mathrm{~V}$ were 8.6, 10.1, 11.2 and 15.6 mA, respectively. The higher slopes at 2 and $2.3 \mathrm{~V}$ were mainly contributed by the higher external voltage. The lowest currents appeared in $1.5 \mathrm{~V}$ could be explained by that the amount of electrons became the limiting factor of nitrate reduction when voltage was too low as $1.5 \mathrm{~V}$. Additionally, the sensor exhibited high linearity more than $90 \%$ at all voltages, illustrating the good performance under different voltages.

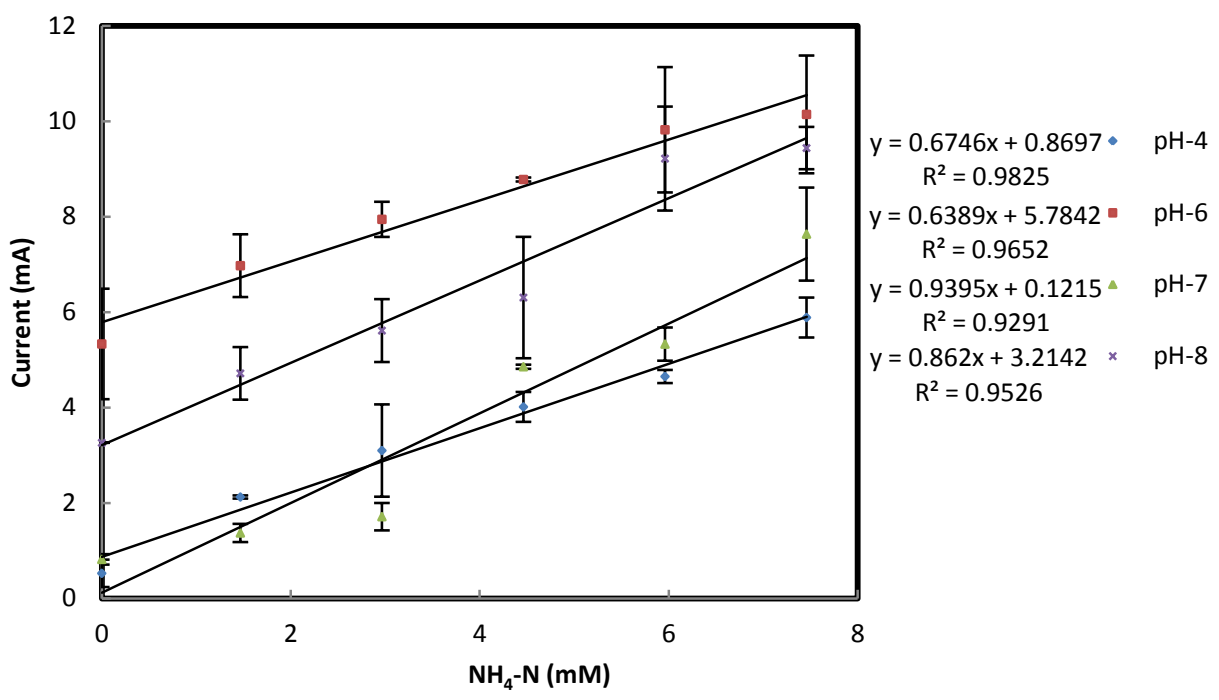

Figure. 5 Effect of $\mathrm{pH}$ on the performance of ammonia monitoring at external applied voltage of $1.8 \mathrm{~V}$.

Different $\mathrm{pH}$ of AD digesters are usually observed in various kinds of studies (Cook et al., 2017). Thus, it's vital to investigate the influence of $\mathrm{pH}$ on sensor performance. In order to achieve this goal, different $\mathrm{pH}$ of synthetic wastewater were tested. The results are displayed in Fig.5. It was observed that at all pH conditions, the currents always increased linearly with ammonia levels. The slopes for $\mathrm{pH} 4, \mathrm{pH} 6, \mathrm{pH} 7$ and $\mathrm{pH} 8$ were 
$0.6746,0.6389,0.9395$ and 0.862 , respectively. The higher slopes tented to be achieved in neutral and weak alkaline condition. However, it should be noticed that higher currents were observed in weak acid environment ( $\mathrm{pH}$ 6). For example, when with the initial ammonia concentration was $4.5 \mathrm{mM} \mathrm{NH}{ }_{4}^{+}-\mathrm{N}$, the currents at pH 6 and pH-8 were 8.8 and 6.3 mA, respectively. As shown in Fig.5, the current generation at weak acid condition ( $\mathrm{pH} \mathrm{6)}$ actually exhibited a higher value compared to the neutral and weak alkaline condition. It has been reported that the weak acid condition may favour electrochemical nitrate reduction (Abdallah et al., 2014). Moreover, the correlation coefficients for $\mathrm{pH} 4, \mathrm{pH} \mathrm{6,pH} 7$ and $\mathrm{pH} 8$ were 0.9825 , 0.9652, 0.9291 and 0.9526 , respectively. The sensor showed high linearity at all tested $\mathrm{pH}$ conditions.

\subsection{Monitoring performance under the interference from other electron acceptors}
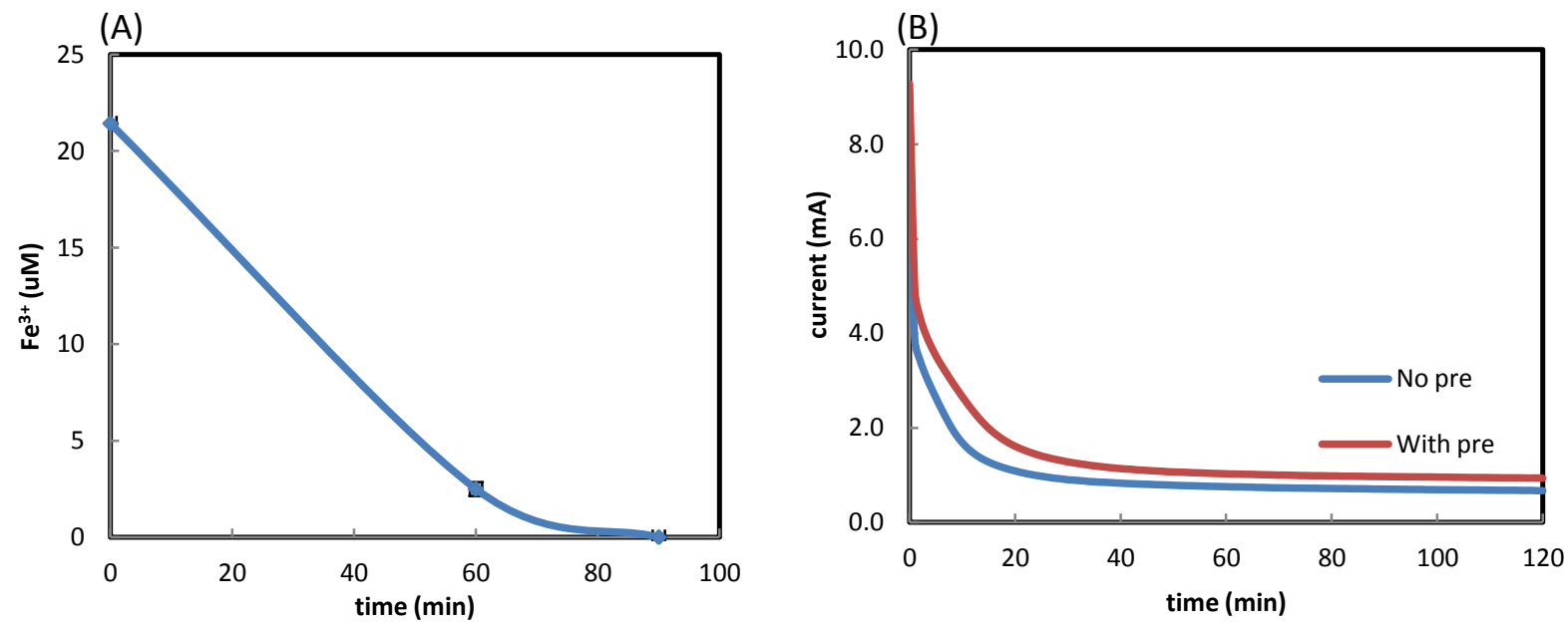

Figure. 6 The change of $\mathrm{Fe}^{3+}$ concentration (A) and current generation (B) over time in EC reactor. The operational parameters: external voltage of pretreatment is $4 \mathrm{~V}$, initial $\mathrm{pH}$ is 6 and initial $\mathrm{NH}_{4}{ }^{+}-\mathrm{N}$ of $6 \mathrm{mM}$ in synthetic water.

In order to avoid the interferences from other possible electron acceptors, the wastewater was firstly introduced to the cathode of EC reactor before nitrification. The synthetic wastewater with $21.4 \mathrm{uM} \mathrm{Fe}^{3+}$ was used for the test. Fig.6 (A) shows the variations of $\mathrm{Fe}^{3+}$ concentration over time in the EC during pretreatment. It is clear from this figure that $\mathrm{Fe}^{3+}$ was removed totally within 90 minutes when external voltage was applied to $4 \mathrm{~V}$. The removal mechanism was mainly electrochemical reduction in cathode. Fig.6 (B) displays the change of biosensor current over time with and without pre-treatment in the EC reactor. For 
both conditions, the fast decrease of current within 20 minutes was observed. The stable current of biosensor with pre-treatment was $0.93 \mathrm{~mA}$, while it was $0.67 \mathrm{~mA}$ for the biosensor without pre-treatment. The student's test was conducted to evaluate the significant difference between two series of data. At $99 \%$ confidence level, there was a significant difference between the current generations in two cases. The results demonstrated that EC pretreatment before nitrification could be an efficiency method to eliminate the disturbance from other electron acceptors in the AD effluent.
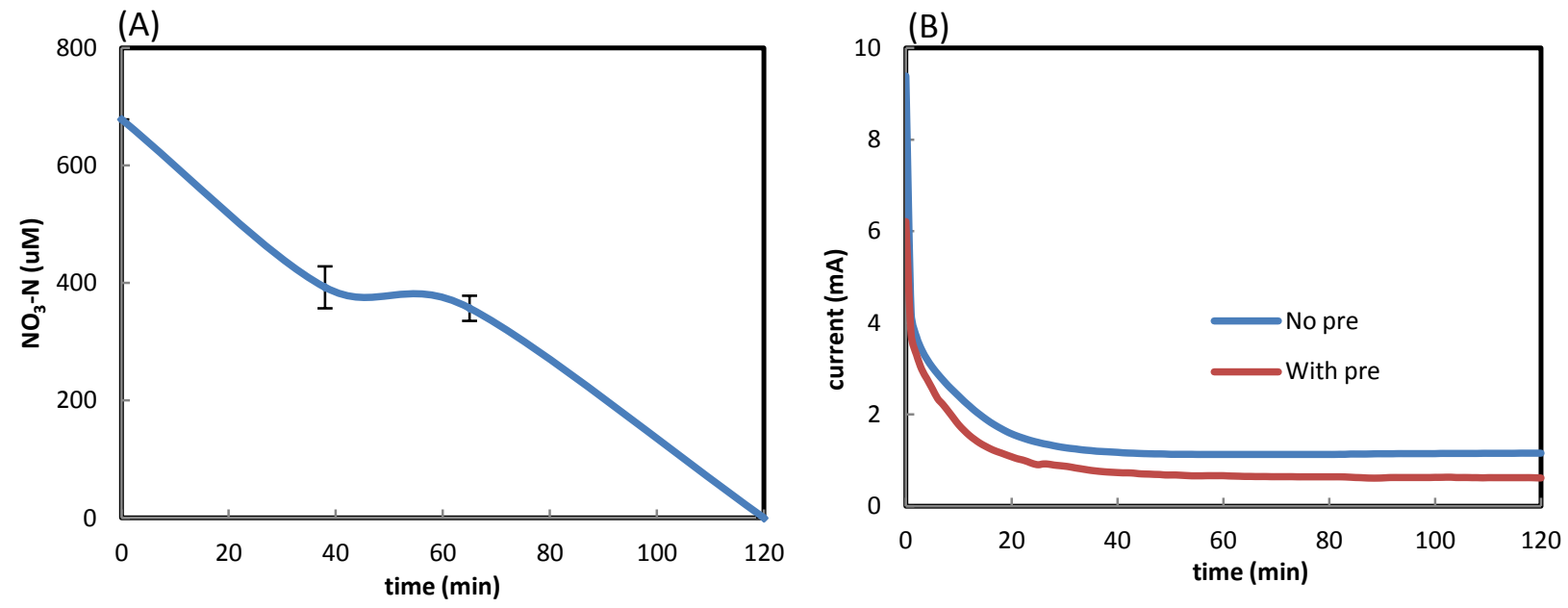

Figure. 7 The change of $\mathrm{NO}_{3}{ }^{-} \mathrm{N}$ concentration (A) and current generation (B) over time in EC reactor. The operational parameters: external voltage of pretreatment is $4 \mathrm{~V}$, initial $\mathrm{pH}$ is 6 and initial $\mathrm{NH}_{4}{ }^{+}-\mathrm{N}$ of $80 \mathrm{mg} / \mathrm{L}$ in synthetic water.

Likewise, the nitrate, as another important electron acceptor in water, is also not negligible. To explore if the EC pretreatment also works for the removal of $\mathrm{NO}_{3}^{-}-\mathrm{N}$ before nitrification, the synthetic wastewater enriched with $714.3 \mathrm{uM} \mathrm{NO}{ }_{3}^{-} \mathrm{N} / \mathrm{L}$ was used for the test. As displayed in Fig.7 (A), the nitrate showed a gradual decrease within 2 hours owing to cathodic electrochemical reduction when $4 \mathrm{~V}$ was applied. Fig.7 (B) shows the current change in the biosensor with and without EC pretreatment. Similarly, the results of student's ttest showed a significant difference between two situations at $99 \%$ confidence level, showing the importance of EC pretreatment for the accurate sensing. To conclude, the effects of $\mathrm{Fe}^{3+}$ and $\mathrm{NO}_{3}^{-} \mathrm{-}$ on sensor performance could be eliminated through the pre-treatment using EC, which could improve the stability 
during ammonia monitoring with complex waste streams. But for AD process, electron acceptors such as $\mathrm{Fe}^{3+}$ and $\mathrm{NO}_{3}{ }^{-} \mathrm{N}$ may not be existence, since they would be reduced by receiving the electrons from microbial oxidation of organics. Thus, pretreatment may not be necessary for ammonia monitoring of AD digestate. But the results offer insight into the extended application feasibility of the sensor for other water treatment processes.

\subsection{Application in real AD effluent}

Table. 1 Determination of $\mathrm{NH}_{4}{ }^{+}-\mathrm{N}$ in real waste streams by EC-nitrification based biosensor and ammonia testing kit.

\begin{tabular}{ccccc}
\hline sample & $\mathrm{NH}_{4}{ }^{+}-\mathrm{N}^{\mathrm{a}}$ & $\mathrm{NH}_{4}{ }^{+}-\mathrm{N}^{\mathrm{b}}$ & $\mathrm{pH}$ & $\begin{array}{c}\text { Conductivity } \\
\text { (us/cm) }\end{array}$ \\
\hline AD effluent 1 & $1542.30 \pm 5.12$ & $1647.8 \pm 13.18$ & $8.87 \pm 0.10$ & $1690 \pm 2$ \\
AD effluent 2 & $917.24 \pm 2.16$ & $987.5 \pm 20.04$ & $8.20 \pm 0.10$ & $1329 \pm 5$ \\
\hline
\end{tabular}

a: tested by fast kits. b: measured by sensor.

To verify the applicability for real digestate, the biosensor was further tested with two real AD effluents. The samples were stored at $4{ }^{\circ} \mathrm{C}$ and fluxed with nitrogen before used. The ammonia levels obtained from fast kits and biosensor along with primary characteristics of two effluents were summarized in Table 1. Anova analysis was performed to investigate the difference between values tested with two methods. The results showed no significant difference between the results obtained from the two methods $(\mathrm{P}>0.05)$ at $95 \%$ confidence level, which confirmed a good accuracy of the biosensor. According to the results, the sensor could monitor the $\mathrm{AD}$ samples with a wide range of ammonia levels.

\section{Conclusions}

The present study for the first time demonstrated the feasibility of integrated EC-nitrification process for ammonia monitoring during AD process. It was observed that the sensor responded immediately within 5 minutes to a stepwise increasing of ammonia level from 0 to $7.5 \mathrm{mM} \mathrm{NH}_{4}{ }^{+}-\mathrm{N}$. Linear relationships between current and ammonia concentration were always observed regardless of voltage and $\mathrm{pH}$. Additionally, EC could pre-remove potential electron acceptors before monitoring. Finally, the sensor showed high accuracy 
and sensitivity to real AD effluents. Though promising, more efforts are still needed to further improve the sensor by simplifying reactor configuration, shortening aerobic process etc.

\section{Acknowledgements}

The authors would like to acknowledge China Scholarship Council for the finial support. The authors thank the technical assistance by Hector Gracia and Illia with offering AD effluents from her reactor. This research was supported financially by The Danish Council for Independent Research (DFF-1335-00142).

\section{References}

Abass, A.K., Hart, J.P., Cowell, D.C., Chappell, A., 1998. Development of an amperometric assay for NH4_+ based on a chemically modified screen-printed NADH sensor. Analytica Chimica Acta 373, 1-8.

Abdallah, R., Geneste, F., Labasque, T., Djelal, H., Fourcade, F., Amrane, A., Taha, S., Floner, D., 2014. Selective and quantitative nitrate electroreduction to ammonium using a porous copper electrode in an electrochemical flow cell. Journal of Electroanalytical Chemistry 727, 148-153.

Angelidaki, I., Ahring, B.K., 1994. Anaerobic thermophilic digestion of manure at different ammonia loads effect of temperature. Water Research 28, 727-731.

Bertocchi, P., Compagnone, D., Palleschi, G., 1996. Amperometric ammonium ion and urea determination with enzyme-based probes. Biosens. Bioelectron. 11, 1-10.

Chatterjee, B., Mazumder, D., 2016. Anaerobic digestion for the stabilization of the organic fraction of municipal solid waste: A review. Environmental Reviews 24, 426-459.

Choong, Y.Y., Norli, I., Abdullah, A.Z., Yhaya, M.F., 2016. Impacts of trace element supplementation on the performance of anaerobic digestion process: A critical review. Bioresource Technology 209, 369-379. Cook, S.M., Skerlos, S.J., Raskin, L., Love, N.G., 2017. A stability assessment tool for anaerobic codigestion. Water Res 112, 19-28.

Hansen, K.H., Angelidaki, I., Ahring, B.K., 1998. Anaerobic digestion of swine manure: Inhibition by ammonia. Water Research 32, 5-12.

Herzog, G., 2015. Recent developments in electrochemistry at the interface between two immiscible electrolyte solutions for ion sensing. Analyst 140, 3888-3896. 
Huang, X.Y., Li, X.M., Li, Y., Yang, J.C., Tao, C.Y., 2016. Trace dissolved ammonia sensor based on porous polyelectrolyte membrane-coated thin-core fiber modal interferometer. Sens. Actuator B-Chem. 226, $7-13$.

Krug, F.J., Ruzicka, J., Hansen, E.H., 1979. Determination of ammonia in low concentrations with Nesslers reagent by flow injection analysis. Analyst 104, 47-54.

Le, P.T.T., Boyd, C.E., 2012. Comparison of Phenate and Salicylate Methods for Determination of Total Ammonia Nitrogen in Freshwater and Saline Water. Journal of the World Aquaculture Society 43, 885-889. Luo, Y.C., Do, J.S., 2006. Amperometric ammonium ion sensor based on polyaniline-poly (styrene sulfonate-co-maleic acid) composite conducting polymeric electrode. Sensors and Actuators B-Chemical 115, $102-108$.

Ning, Y.F., Yan, P., Chen, Y.P., Guo, J.S., Shen, Y., Fang, F., Tang, Y., Gao, X., 2017. Development of a Pt modified microelectrode aimed for the monitoring of ammonium in solution. Int. J. Environ. Anal. Chem. 97, 85-98.

Radjenovic, J., Sedlak, D.L., 2015. Challenges and Opportunities for Electrochemical Processes as NextGeneration Technologies for the Treatment of Contaminated Water. Environ Sci Technol 49, 11292-11302. Rajagopal, R., Masse, D.I., Singh, G., 2013. A critical review on inhibition of anaerobic digestion process by excess ammonia. Bioresource Technology 143, 632-641.

Rajmohan, K.S., Gopinath, M., Chetty, R., 2016. Review on challenges and opportunities in the removal of nitrate from wastewater using electrochemical method. J.Environ.Biol. 37, 1519-1528.

Rayner, A.J., Briggs, J., Tremback, R., Clemmer, R.M.C., 2017. Design of an organic waste power plant coupling anaerobic digestion and solid oxide fuel cell technologies. Renew. Sust. Energ. Rev. 71, 563-571. Ribeiro, J.A., Silva, F., Pereira, C.M., 2012. Electrochemical sensing of ammonium ion at the water/1,6dichlorohexane interface. Talanta 88, 54-60.

Samarasinghe, S., Shao, Y., Huang, P.J., Pishko, M., Chu, K.H., Kameoka, J., 2016. Fabrication of Bacteria Environment Cubes with Dry Lift-Off Fabrication Process for Enhanced Nitrification. PLoS One 11, 11. Senghor, A., Dioh, R.M.N., Muller, C., Youm, I., 2017. Cereal crops for biogas production: A review of possible impact of elevated CO2. Renew. Sust. Energ. Rev. 71, 548-554. 
Shanahan, J.W., Semmens, M.J., 2015. Alkalinity and $\mathrm{pH}$ effects on nitrification in a membrane aerated bioreactor: an experimental and model analysis. Water Res 74, 10-22.

Tao, S.Q., Xu, L., Fanguy, J.C., 2006. Optical fiber ammonia sensing probes using reagent immobilized porous silica coating as transducers. Sens. Actuator B-Chem. 115, 158-163.

Tarre, S., Green, M., 2004. High-rate nitrification at low pH in suspended- and attached-biomass reactors. Appl Environ Microbiol 70, 6481-6487.

Wang, L., Zheng, P., Abbas, G., Xing, Y.J., Li, W., Wang, R., Deng, L.W., Lei, Y.H., Zheng, D., Zhang, Y.H., 2016. Enrichment and characterization of acid-tolerant nitrifying sludge. J. Environ. Manage. 184, 196-203.

Zhang, Y., Love, N., Edwards, M., 2009. Nitrification in Drinking Water Systems. Crit. Rev. Environ. Sci. Technol. 39, 153-208.

Zhou, L., Boyd, C.E., 2016. Comparison of Nessler, phenate, salicylate and ion selective electrode procedures for determination of total ammonia nitrogen in aquaculture. Aquaculture 450, 187-193.

Zhybak, M.T., Vagin, M.Y., Beni, V., Liu, X.J., Dempsey, E., Turner, A.P.F., Korpan, Y.I., 2016. Direct detection of ammonium ion by means of oxygen electrocatalysis at a copper-polyaniline composite on a screen-printed electrode. Microchimica Acta 183, 1981-1987.

Zolotov, S.A., Vladimirova, E.V., Dunaeva, A.A., Shipulo, E.V., Petrukhin, O.M., Vatsuro, I.M., Kovalev, V.V., 2014. Determination of the ammonium ion by voltammetry at the liquid-liquid interface using calixarenes as neutral carriers. Russian Journal of Electrochemistry 50, 940-946. 


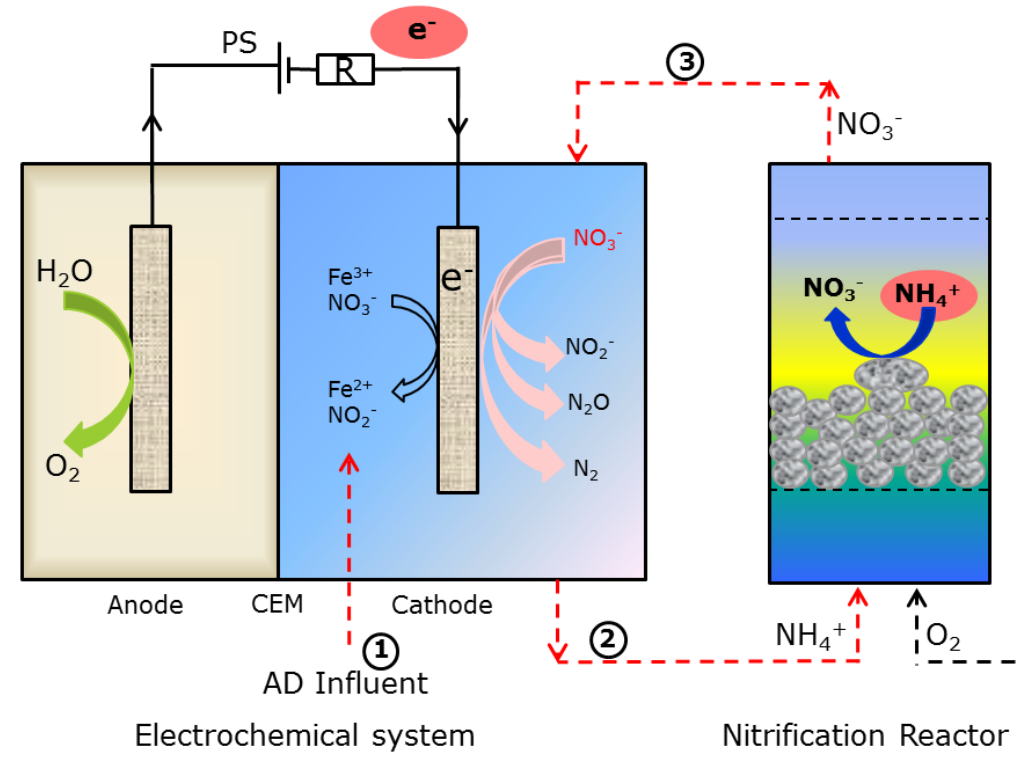

